
Military Technical College Kobry El-Kobbah, Cairo, Egypt.

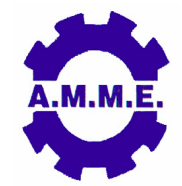

\title{
EFFECT OF AXIAL GAP ON THE AERODYNAMICS OF 1 AND 1.5 STAGE TURBINES
}

\author{
R. Subbarao* and M. Govardhan ${ }^{*}$
}

\begin{abstract}
Axial gap is one of the few important parameters that affect the performance of a turbine. Present work involves the computational study in 1 and 1.5 stage turbines with axial gaps of $15 \%$ and $50 \%$. For each axial gap, investigation is done at three flow coefficients; namely, $0.68,0.78$ and 0.96 . The turbine components nozzle, rotor and stator are modeled for both the axial gaps. Mid-span pressure distribution of the rotor for the design configuration is compared with the experimental results and found to be in good agreement. Total pressure, axial velocity, entropy and Mach number distributions along with torque are analyzed for all the configurations. Results indicate that the performance of the turbine is dependent on axial gap.
\end{abstract}

\section{KEY WORDS}

Axial flow turbine, axial gap, flow coefficient, pressure distribution, one and one-half stage, turbine performance.

* Research Scholar, Dept. of Mechanical Engineering, IIT Madras, Chennai, India.

** Professor, Dept. of Mechanical Engineering, IIT Madras, Chennai, India. 


\title{
NOMENCLATURE
}

\author{
ch Chord length $(m)$ \\ $\mathrm{C}_{\mathrm{p}} \quad$ Pressure coefficient, $\frac{p-p_{\text {static out }}}{P_{\text {totai, in }}-P_{\text {static }} \text {, put }}$ \\ $\mathrm{C}_{\mathrm{m}} \quad$ Axial velocity $(\mathrm{m} / \mathrm{s})$ \\ P Pressure $\left(\mathrm{N} / \mathrm{m}^{2}\right)$ \\ $r \quad$ Radius $(m)$ \\ T Temperature $(\mathrm{K})$ \\ $U \quad$ Blade speed $(\mathrm{m} / \mathrm{s})$ \\ $\mathrm{x}, \mathrm{y}, \mathrm{z}$ Distances in $\mathrm{x}, \mathrm{y}, \mathrm{z}$ co-ordinate system (m)
}

\section{Greek Letters}

$\phi \quad$ Flow coefficient

$\rho \quad$ Density $\left(\mathrm{kg} / \mathrm{m}^{3}\right)$

\section{Subscripts}

$\begin{array}{ll}\text { h } & \text { Hub } \\ \text { o } & \text { Total } \\ \text { t } & \text { Tip }\end{array}$

\section{INTRODUCTION}

Research carried out till now in gas turbine technologies has been quite successful in improving the performance that would reduce the running cost and use the limited energy resources available. Mere 1\% improvement in the efficiency of commercial aircraft engines would result in substantial savings. The mechanical and aerodynamic performances of the turbine influence the other components running in the same system. Thus, it has been the prime interest of the researchers to investigate their performance by various means and study the aerodynamics of the flow in a turbine stage which is complex. Improved experimental and computational methods have been applied both to entire machines and to the individual components to get proper understanding. From the studies conducted, it is found that axial gap and flow coefficient along with few other parameters play a major role in the performance of the turbine. In the past, the design of axial flow machines was based on the experimental evidence of a large number of cascade tests, but the results obtained could be very limited, and the range of test conditions are relatively narrow. In addition, running costs are usually very high.

In the recent years, the development of computer technology and the progress achieved in numerical methods has made Computational Fluid Dynamics (CFD) a better alternative. The ability to model and simulate the complex flow phenomena inside the turbomachinery passages with good accuracy can provide reliable guidance in designing the next generation turbines. CFD really provides the ability to exploit the three-dimensional nature of the flow to control undesirable features such as corner flow separations in compressors or strong secondary flows in turbines (Horlock and Denton, [1]). Studies have been made to investigate the effect of axial 
gap on the aerodynamic performance of the turbine stage, and some efforts among them revealed the importance of unsteadiness and the mechanism of the losses in turbomachinery. Venable et al. [2] varied the vane-blade spacing in a transonic turbine and reported the tendency of adiabatic efficiency increase when the rotorstator axial gap is increased. He [3] made three-dimensional unsteady Navier Stokes analysis of stator-rotor interaction and established the same result. Yamada et al. [4] studied the influence of axial gap between the blade rows on the aerodynamic performance in a turbine stage and found increment of axial gap to be advantageous. On the other hand, the experimental and numerical analysis of Jeong et al. [5] revealed decrement of efficiency with the increase in axial gap in case of a supersonic impulse turbine. Also, Gaetani et al. [6], Funazaki and Sato [7], Kikuchi et al. [8] and Gronman et al. [9] reported that it was possible to achieve higher turbine efficiency with decreased axial spacing. Investigations on impulse turbine by Sadovnichiy et al. [10] revealed decrement in efficiency when the axial gap was increased for one configuration, but for another configuration the efficiency remained almost unchanged. While all these mentioned studies have been on a single stage turbine, few others conducted studies on one and one-half stage. Crosh et al. [11] examined the effect of rotor casing distortion on the aerodynamics of a one and onehalf stage high pressure turbine. Mathison et al. [12] have dealt with the experimental and CFD analyses of upstream and downstream pressures of the turbine stage are presented.

Efficiency drop with increased axial gap is mainly due to increasing total pressure losses and more diffused passage vortices and wakes in the stator passage along with increased incidence due to pressure gradients in the radial direction. Also, loss of flow velocity at the rotor inlet when the axial gap is increased supports the idea of small gap. Conversely, studies showed that the size of the rotor passage vortices decreased as the gap is decreased indicating that larger gap would be beneficial. Since the performance scenario with respect to axial gap is not clear from the literature, it is needed to conduct a study that would bring more information about the effect of this constraint. In the present work, the effect of varying axial gap and flow coefficient on the performance and flow field of an axial flow turbine for both 1 and 1.5 stages is studied. Analysis is carried out for flow coefficients of $0.68,0.78$ and 0.96 with axial gaps of $15 \%$ and $50 \%$ of the average of rotor and stator axial chords.

\section{METHODOLOGY}

Single stage turbine consists of nozzle and rotor respectively. One and a half stage includes downstream stator. Details of the geometric configuration obtained from Dring et al. [13] are shown in Table 1. Tip clearance is considered for the rotor. Each axial gap and stage requires the modeling and grid generation of fluid domain consisting of all the components. Model is generated using the Cartesian coordinates for the hub, shroud and blade. X-axis is chosen as the axis of revolution. Computational domains generated for both the stages are as shown in Fig.1. Flow is treated as periodic, so instead of modeling the entire rotor or stator, modeling of one blade passage is done by applying periodic condition. This reduces the computational time and cost substantially. For grid generation, tetra meshing is used. Tetra takes full advantage of object-oriented unstructured meshing technology. Tetra works directly from the geometry surfaces and fills the volume with tetrahedral 
elements using Octree-based meshing algorithm to fill the volume with tetrahedral cells and generates a surface mesh on the object surfaces. For improved mesh quality, it incorporates a powerful smoothening algorithm as well as tools for local adaptive mesh refinement and coarsening. For better modeling of near-wall physics of the flow field, prism meshing is done that consists of layers near the boundary surfaces and tetrahedral elements in the interior. Modeling and meshing of the computational domain are done using the commercial software ANSYS® ICEM CFD 13.0. Mesh distribution is done to provide sufficiently large number of elements in the tip clearance region, near the leading and trailing edges and around the blade. Nozzle, Rotor and Stator consist of about 1.8, 1.6 and 2.2 million elements respectively. CFX 13.0 is used for simulations.

\section{FLOW AND BOUNDARY CONDITIONS}

Boundary conditions are imposed on the nozzle inlet and rotor outlet in single stage case. In case of one and a half stage, conditions are imposed on nozzle inlet and stator outlet. Mass flow rate/flow speed is specified at inlet and static pressure is given at outlet. Flow conditions are as shown in Table 1. Inlet flow is assumed to be uniform with no swirl. Air ideal gas is considered as the working fluid. On the blade, hub and shroud surface, no slip condition is assumed. Adiabatic condition is assumed for the walls. Frozen rotor interface is chosen for the rotor-stator frame change interface. With this interface modeling, frame of reference and/or pitch is changed but the relative orientation of the components across the interface is fixed. The two frames of reference connect in such a way that both have fixed relative position throughout the calculation. The plane in between two adjacent blades is taken as periodic. These planes on either side of the blade will make periodic pair of surfaces. Rotational periodicity is enforced about the axis of rotation. All surfaces viz. hub and shroud end walls and the blade surfaces are given smooth wall with no-slip boundary condition. Rotor casing surface is defined as a counter-rotating wall in the rotating frame of reference. This is equivalent to stationary wall in the stationary frame of reference. Currently, the most prominent two-equation models in this area are the $k-\omega$ based models of Menter [14]. Standard k- $\omega$ based Shear Stress Transport (SST) model is used as it accounts for the transport of turbulent shear stress and the amount of flow separation under adverse pressure gradients by the inclusion of transport effects into the formulation of eddy viscosity giving highly accurate predictions. This results in a major improvement in terms of flow separation predictions. The superior performance of this model has been demonstrated in a large number of validation studies (Bardina et al. [15]). Grid independence study is carried by changing the number of mesh elements.

The governing equations are integrated over each control volume in such a way that mass, momentum, energy etc. are conserved in a discrete sense for each control volume. The Continuity equation is,

$\nabla \bullet(\rho \boldsymbol{C})=0$

where $\mathrm{C}$ is velocity vector. The Momentum equation is, 


$$
\nabla \bullet(\rho \boldsymbol{C} \otimes \boldsymbol{C})=\nabla \bullet\left(-\rho \delta+\mu\left(\nabla \boldsymbol{C}+(\nabla \boldsymbol{C})^{T}\right)\right)+S_{M}
$$

where, $S_{M}$ is source term for momentum. The energy equation is given by,

$$
\nabla \bullet\left(\rho C h_{o}\right)=\nabla \bullet(\lambda \nabla T)+S_{E}
$$

Where, $S_{E}$ is the source term for energy. CFX provides the solution of these governing equations by discretising the domain into finite control volume mesh.

\section{RESULTS AND ANALYSIS}

\section{Validation}

Simulation results are validated with the experiments conducted in a large scale rotating turbine rig at the United Technologies Research Center (UTRC), USA. In this work, $C_{p}$ distribution is used for comparison with the experimental values of Dring et al.[13]. Figure 2 shows the comparison of simulation and experimental results for $\mathrm{x} / \mathrm{ch}=0.5$ in case of one and one-half stage. The flow at the mid span on the rotor is well behaved on both pressure and suction surfaces. The agreement is excellent except for a small region on the suction side where the peak amplitude is shifted to the left of the experimental one.

\section{$C_{p}$ Distribution}

Mid-span $C_{p}$ distribution for the stator is shown in Fig. 3 for $\phi=0.78$ and $x / c h=0.5$ in case of one and one-half stage. This distribution is compared with the experimental results of Dring et al. [13] and potential flow calculations of Caspar et al. [16]. The match between the simulation, potential flow calculation and measured experimental results is good, except in the region rear of the throat on the suction surface. On the whole, the match is good between the simulation and experimentation for all the components. The same pattern is observed in case of other flow coefficients as well.

\section{Pressure, Velocity and Mach Number Distributions}

Figure 4 describes the velocity pattern throughout the one and one-half stage in case of $\mathrm{x} / \mathrm{ch}=0.15$ and 0.5 . On the pressure side velocity increases steadily from the leading edge to the trailing edge because of the reduction in pressure. Along the suction surface, velocity initially increases towards the throat because of the reduced static pressure, starts declining when it encounters the adverse pressure gradients downstream of the throat. The peak velocity corresponds to the location of the minimum $C_{p}$ on the suction surface, as the flow beyond this changes direction and follows the blade shape. In case of rotor, flow on the suction surface, velocity increases first and then deceleration is observed towards the trailing edge. There is a slight speed increment in the flow near the leading edge on both suction and pressure surfaces. In stator, velocity is high near the leading edge. As the gap is decreased from 0.5 to 0.15 , velocity profile showed the same pattern, but magnitude of velocity is not uniform and more disturbing near the leading and trailing edges because of the influence of the wake. On the pressure side of the rotor, velocities are 
slightly higher when the gap is decreased. This clearly indicates that the wake is mixing out resulting in more uniform velocity in $\mathrm{x} / \mathrm{ch}=0.5$ case when compared with $\mathrm{x} / \mathrm{ch}=0.15$. Thus, less resistance is offered at the interface. Similar pattern is observed at all the flow coefficients.

Figure 5 shows static pressure and Mach number distributions in the blade passage. As the incidence is zero, the streamline splits at the stagnation point corresponding to the blade leading edge with one part moving along the pressure side and the other moving along the suction side of the blade. This pressure gradient from the pressure side to the suction side leads to the development of losses. The area near the passage throat, where velocity is high, corresponds to the location where $C_{p}$ is low. Stagnation point region is the one where $C_{p}$ is highest. From the earlier described figures of velocity and pressure, it is clear that flow on the blade suction surface becomes three dimensional and distorted. Also, Figure 5 shows the local Mach number distribution in case of $\mathrm{x} / \mathrm{ch}=0.5$. The flow accelerates over the most of the pressure side except for a short deceleration just downstream of the stagnation point. The flow on the suction side continuously accelerates up to the throat area. At the trailing edge, there is sudden flow deceleration after throat as explained earlier. There is only a slight variation in the local Mach number near the geometric throat.

\section{Flow Field at the Rotor Inlet and Exit}

Figure 6 shows mass averaged radial distribution of normalized axial velocity at the inlet of the rotor for two axial gap cases in a single stage turbine. It is evident that the flow profiles have three-dimensionality, indicating convex and concave nature in the radial direction. The values of axial velocity decreased with increase in axial gap near the tip whereas rise is observed at the hub. This steep variation in the values of $\mathrm{C}_{m}$ is caused by the leakage flow between the rotor tip and the casing. $C_{m}$ variation is linear with the flow coefficient. At the mid-span, the change in axial gap does not have any effect on the velocity distribution. Variation in the pattern of axial velocity at off-design flow coefficients is not significant. As shown in Fig. 7, at the outlet of the rotor, variation of axial velocity with the axial gap is not much at both design and offdesign flow coefficients. Mach number distribution in case of single stage at the rotor inlet and outlet are plotted in Fig. 8. At rotor inlet, the Mach number values are higher at the hub than at the tip. The behaviour is same in case of other flow conditions. But, at the rotor outlet, the Mach numbers increase with the gap up to the mid-span and then decrease slightly less compared to the inlet. Figure 9 shows the entropy distribution at the rotor inlet and outlet in case of single stage. Entropy values are increasing from inlet to the outlet of the rotor because of incurring losses.

\section{Total Pressure Loss and Entropy Drop}

Total pressure variation for a single stage with flow coefficient and axial gap is shown in Fig.10. As the flow coefficient is increased total pressure difference increases. Total pressure changes across the stage with axial gap, although the pattern is same from turbine inlet to outlet. Entropy distribution at the exit of the rotor is shown in Fig. 11. The values of entropy at the corresponding location are less in case of $\mathrm{x} / \mathrm{ch}=0.5$ suggesting better performance due to more uniform flow and velocities. The loss zone is more spread more in case of $x / c h=0.15$. Figure 12 describes the entropy drop across the stage. The drop is less in case of the $\mathrm{x} / \mathrm{ch}=$ 
0.15 . This shows that as the flow coefficient is increased, the drop is more and it reflects in the performance of the turbine. Same scenario is obtained in both 1 and 1.5 stages.

\section{Torque with Axial Gap and Flow Coefficient}

Figure 13 describes the behavior of torque obtained from rotor for both the gaps and stages as the flow coefficient is changed. It is seen that the torque values are slightly changing with respect to the axial gap, suggesting that increment of axial gap is advantageous. At increased mass flow rates, turbines produce more power at a given speed. The increase in torque with flow coefficient is indicated in Fig.13. The rate of increase is high beyond $\phi=0.78$ for both axial gaps. Similar pattern is observed in both 1 and 1.5 stages.

\section{CONCLUSIONS}

In this work, flow and performance parameters of a one and one-half stage turbine are compared with a single stage turbine. The performance of axial flow turbine is clearly dependent on the stator-rotor axial gap. As the gap is increased, wake gets mixed out in the axial gap section resulting more uniform velocity. Entropy at the rotor outlet suggests that losses decrease with the increase of gap. Torque obtained also increase with the gap. Results indicate that increment of axial gap is advantageous. However, studies with more blade configurations, axial gaps, flow coefficients, and tip clearances would definitely provide better understanding of the turbine flow and performance.

\section{REFERENCES}

[1] Horlock, J.H. and Denton, J.D., "A review of some early design practice using computational fluid dynamics and a current prospective", Journal of Turbomachinery, Vol. 127, pp. 5-13, (2005).

[2] Venable, B. L. Delaney, R. A. Busby, J. A. Davis, R. L. Dorney, D. J. Dunn, M. G. Haldeman, C.W. and Abhari, R. S., 1999, "Influence of vane-blade spacing on transonic turbine stage aerodynamics. Part I - time-averaged data and analysis", Journal of Turbomachinery, Vol. 121, pp. 663-672, (1999).

[3] He, L., "Three dimensional unsteady Navier-Stokes analysis of stator-rotor interaction in axial-flow turbines", Proceedings of the Institution of Mechanical Engineers, Part A: Journal of Power and Energy, Vol. 214, No.13, (2000).

[4] Yamada, K. Funazaki, K. Kikuchi, M. and Sato, H., "Influences of axial gap between blade rows on secondary flows and aerodynamic performance in a turbine stage", GT 2009-59855.

[5] Jeong, E. Park, P. K. Kang, S. H. and Kim, J., "Effect of nozzle-rotor clearance on turbine performance", ASME paper FEDSM 2006-98388.

[6] Gaetani, P. Persico, G. Dossena, V. and Osnaghi, C., "Investigation of the flow field in a hp turbine stage for two stator-rotor axial gaps", Part I-3D timeaveraged flow field, GT 2006-90553. 
[7] Funazaki, Y. and Sato H., "Experimental studies on aerodynamic performance and unsteady flow behaviours of a single turbine stage with variable rotor-stator axial gap: Comparisons with time-accurate numerical solution", GT 200727670.

[8] Kikuchi, M. Funazaki, K. Yamada, K. and Sato, H., "Detailed studies on aerodynamic performance and unsteady flow behaviors of a single turbine stage with variable rotor-Stator axial gap", International Journal of Gas Turbine, Propulsion and Power Systems, Vol. 2, No.1, pp. 30-37, (2008).

[9] Gronman A. and Turunen-Saaresti, T., "Design and off-design performance of a supersonic axial flow turbine with different stator-rotor axial gaps", Proc. IMechE Part A: Journal of Power and Energy, Vol. 225, pp. 497-503, (2010).

[10] Sadovnichiy, V.N. Binner, M. and Seume, J.R., "The influence of axial gaps and leaned-twisted guide vanes on the shroud leakage and turbine stage efficiency", Proceedings of the 8th European Conference on Turbomachinery, Graz, Austria, (2009).

[11] Crosh, E. A. Haldeman, C. W. Dunn, M. G. Holmes, D. G. and Mitchell, B. D., "Investigation of Turbine Shroud Distortions on the Aerodynamics of a One and One-Half Stage High-Pressure Turbine," ASME Paper No. GT 2009-59562.

[12] Mathison, R.M. Haldeman, C.W. and Dunn, M.G., "Aerodynamics and heat transfer for a cooled one and one-half stage high-pressure turbine - part I: vane inlet temperature profile generation and migration", Journal of Turbomachinery, Vol. 134, 011006-1, (2012).

[13] Dring, R.P. Joslyn, H.D. and Blair, M.F., "The effect of inlet turbulence and rotor/stator interactions on the aerodynamics and heat transfer of large scale rotating turbine model", NASA CR-179469, (1987).

[14] Menter F.R., "Two-equation eddy-viscosity turbulence models for engineering applications", AIAA-Journal, 32(8), pp. 1598-1605, (1994).

[15] Bardina, J.E., Huang, P.G. and Coakley, T.J., "Turbulence Modeling Validation Testing and Development", NASA Technical Memorandum 110446, (1997).

[16] Caspar, J.R. Hobbs, D.E. and Davis, R.L., "Calculation of two-dimensional potential cascade flow using finite area methods", AIAA Journal, Vol. 18, pp 103-109, (1980).
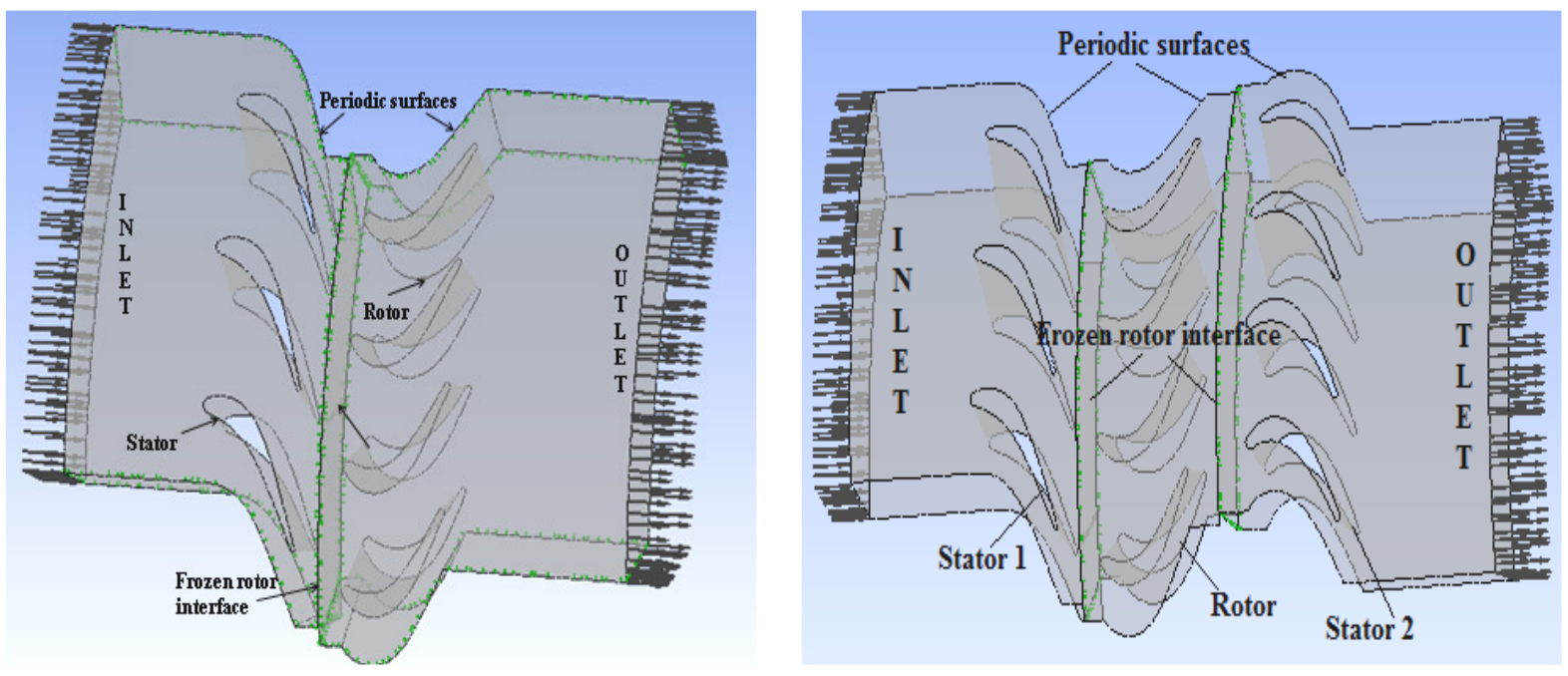

Fig. 1. Computational flow domains used in 1 and 1.5 stages. 


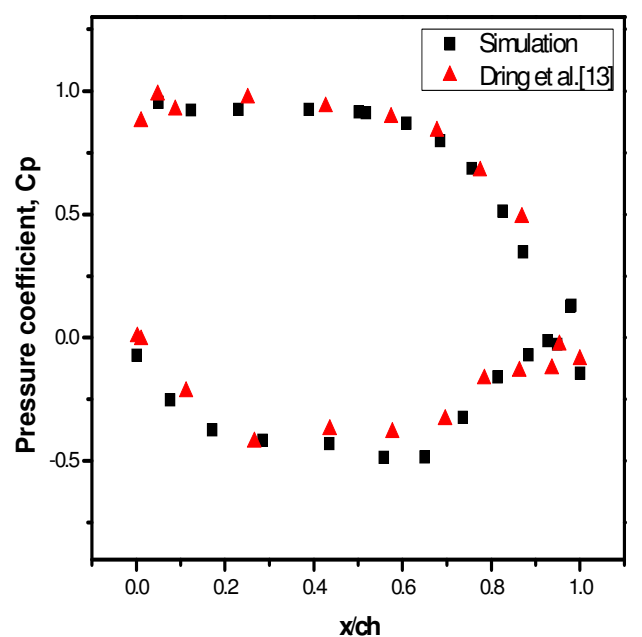

Fig. 2. Mid-span $C_{p}$ distribution of rotor.

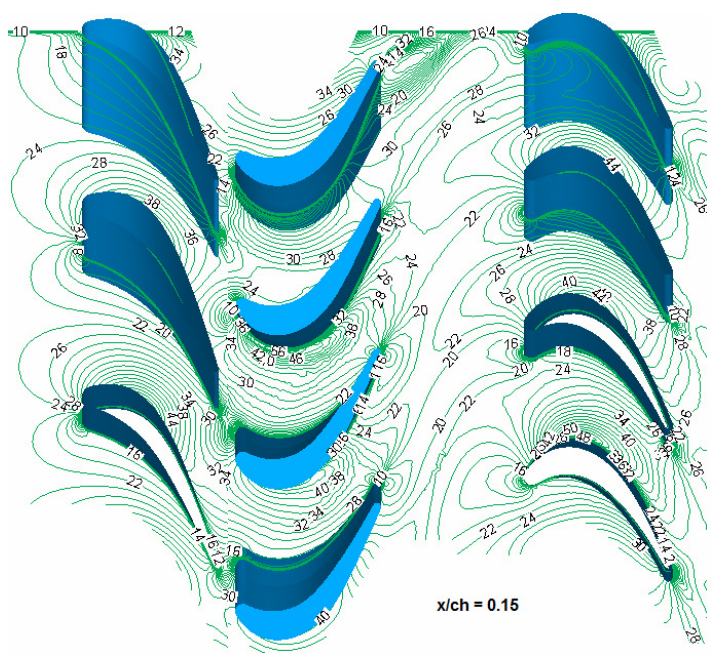

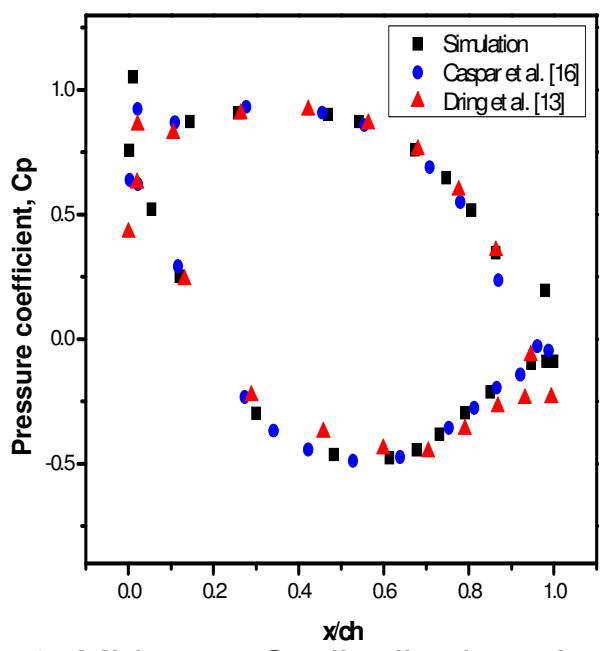

Fig. 3. Mid-span $C_{p}$ distribution of stator.

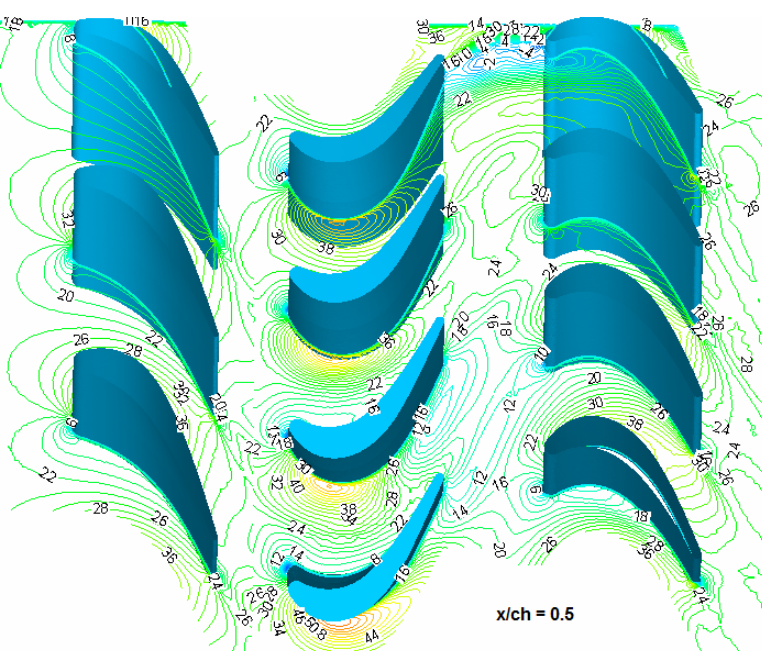

Fig.4. Velocity distribution from inlet to outlet for $\mathrm{x} / \mathrm{ch}=0.15$ and $0.5(\phi=0.78)$.
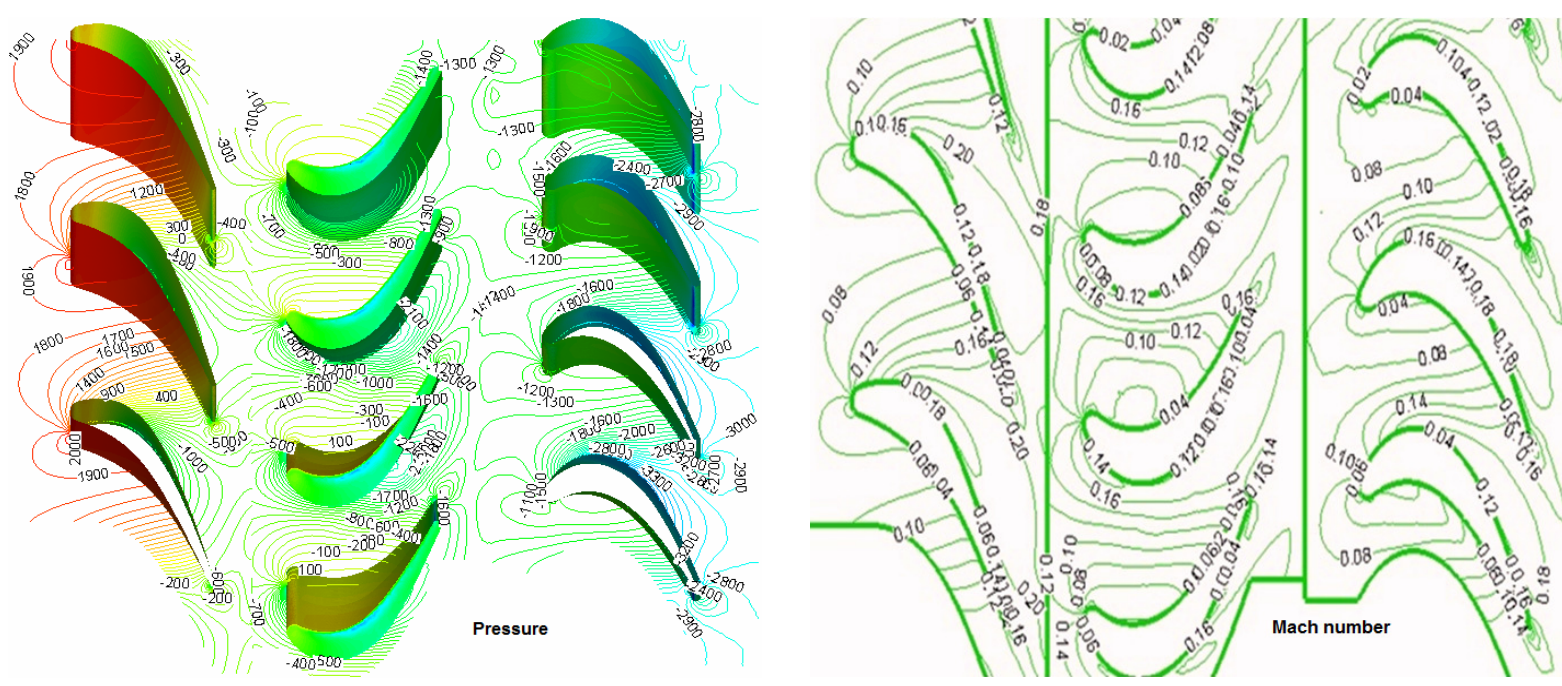

Fig.5. Pressure and Mach number distribution for $\mathrm{x} / \mathrm{ch}=0.5(\phi=0.78)$. 

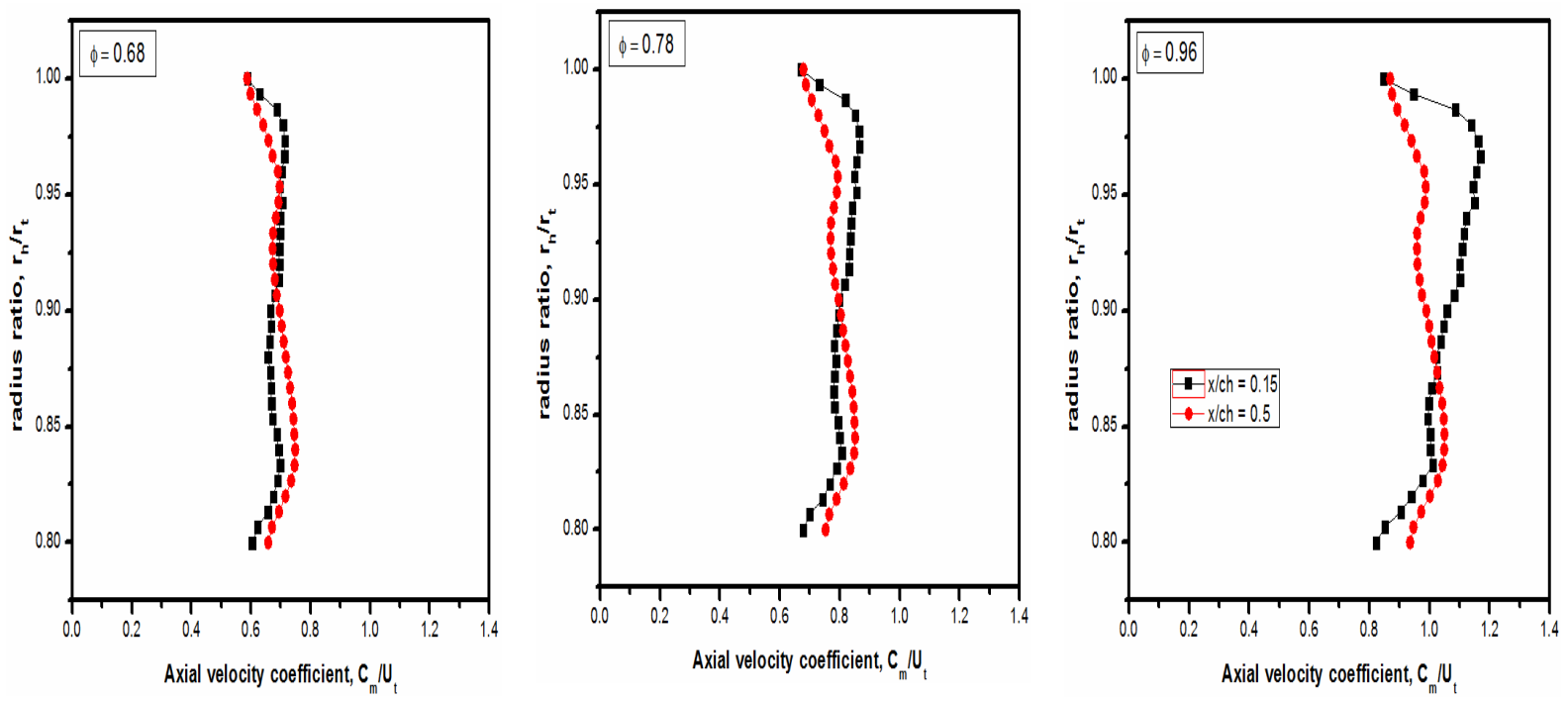

Fig. 6. Axial velocity coefficient, $\mathrm{C}_{m} / \mathrm{U}_{t}$ at rotor inlet for $\phi=0.68,0.78$ and 0.96 .
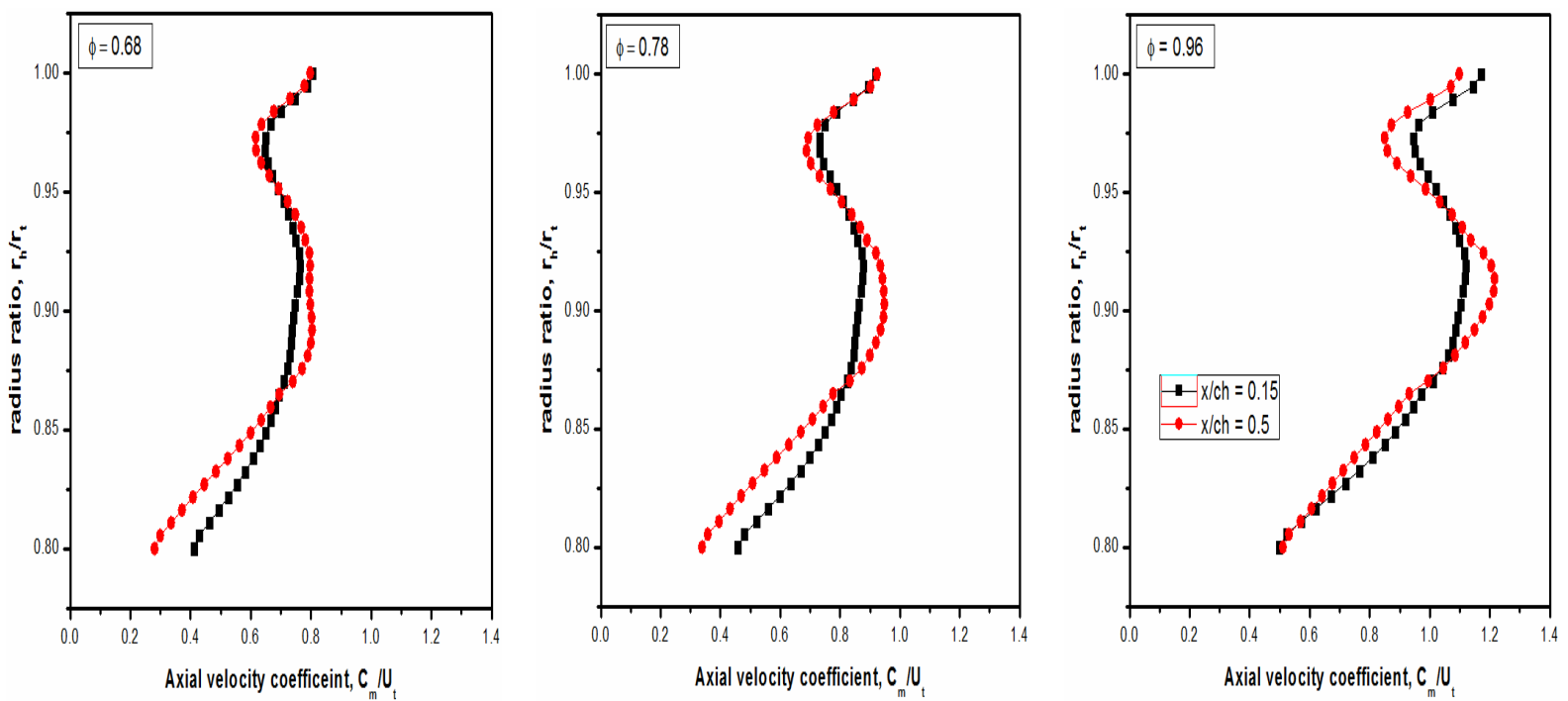

Fig. 7. Axial velocity coefficient, $C_{m} / U_{t}$ at rotor outlet for $\phi=0.68,0.78$ and 0.96 .
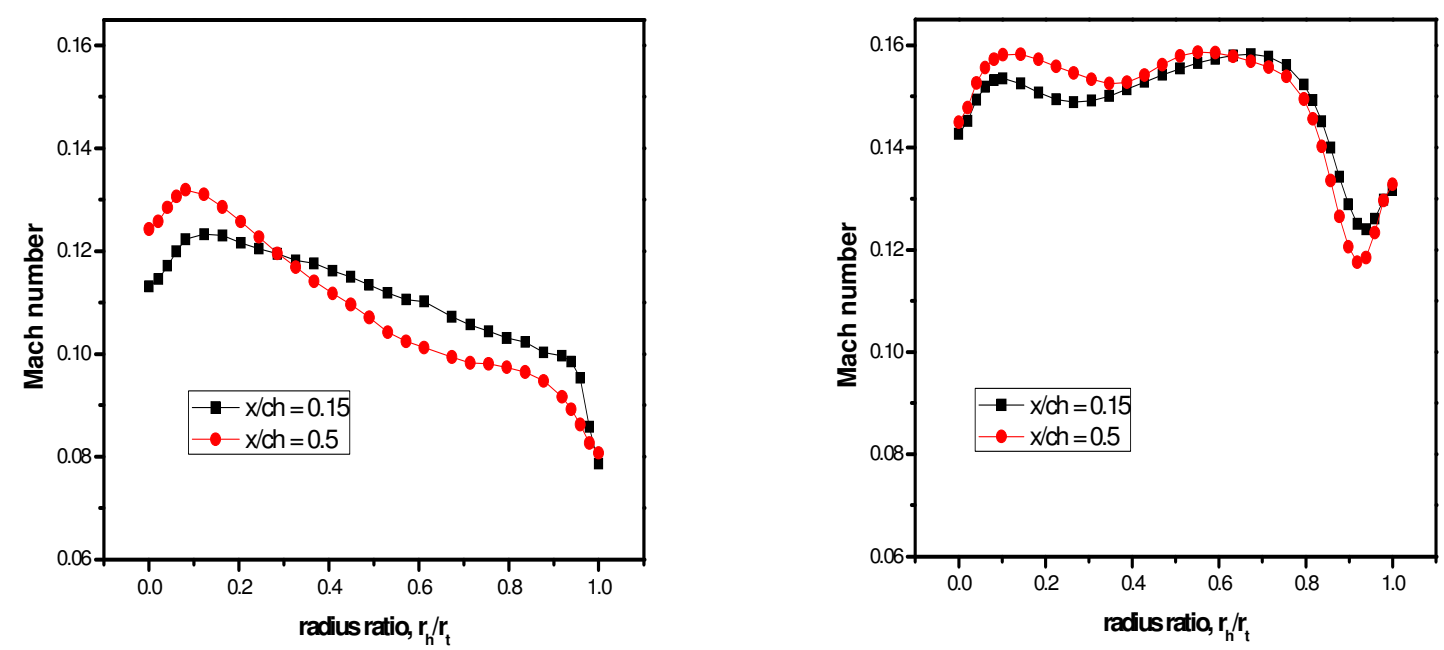

Fig. 8. Mach number distribution at rotor inlet and outlet $(\phi=0.78)$. 

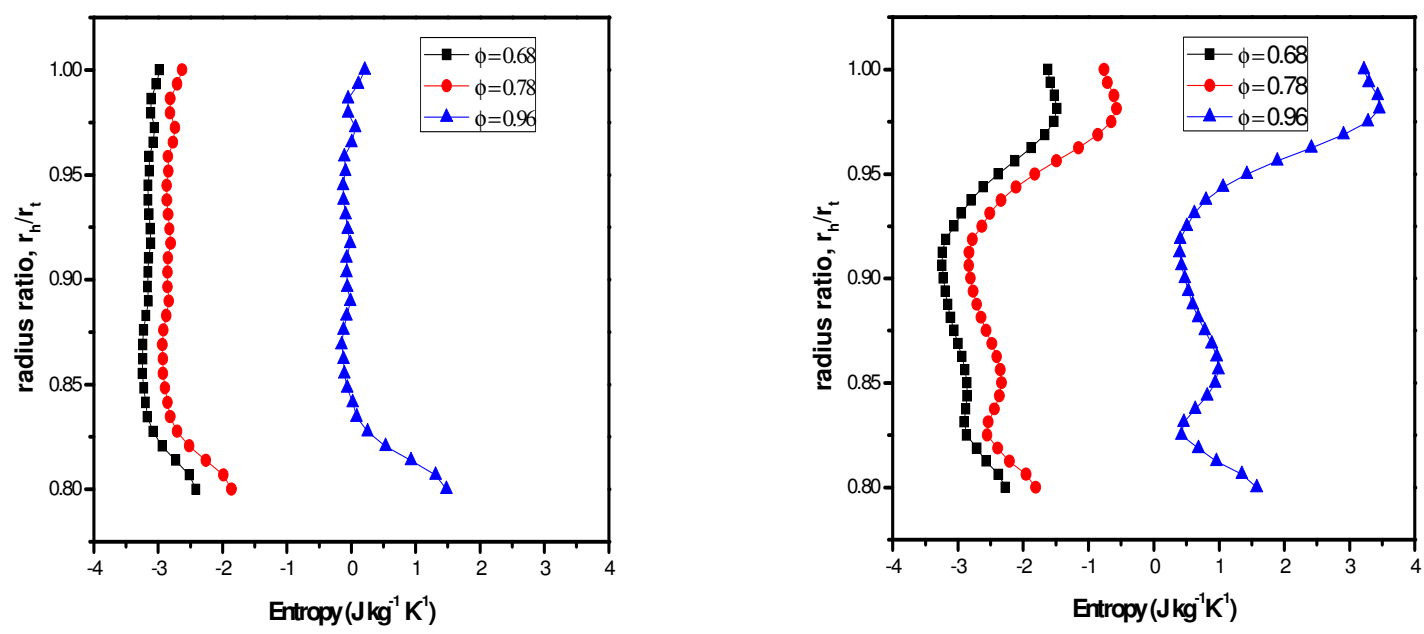

Fig.9. Entropy distribution at inlet and outlet of the rotor for $\mathrm{x} / \mathrm{ch}=0.15$.
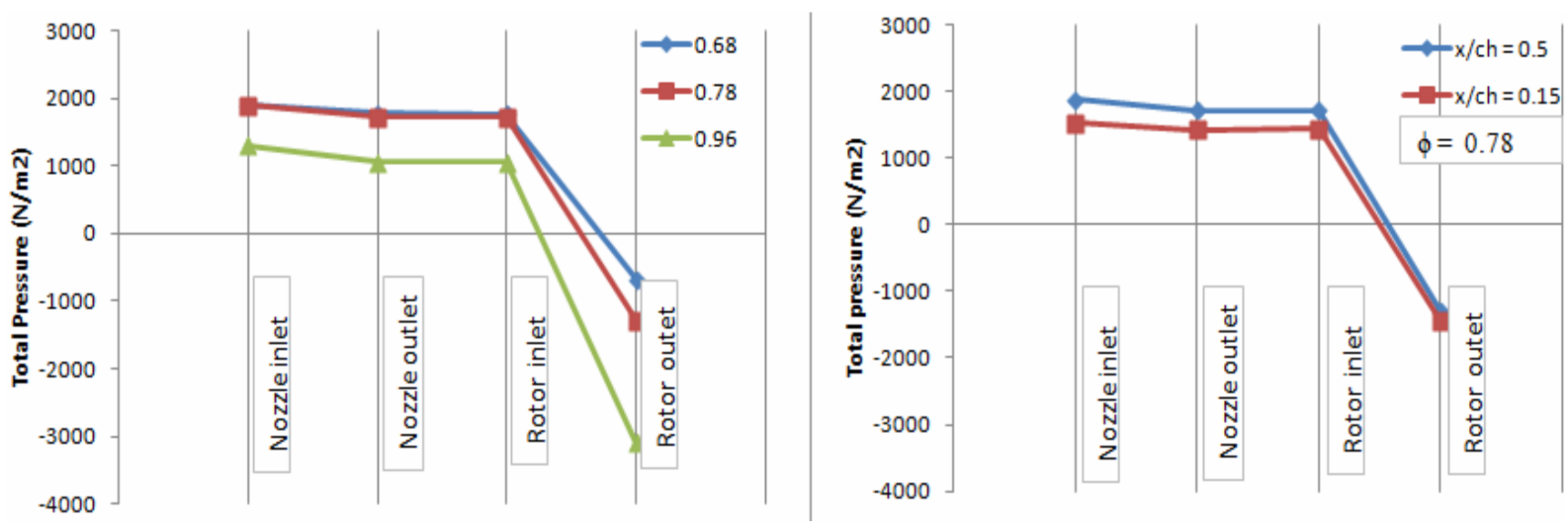

Fig.10. Total pressure variation with flow coefficient and axial gap.
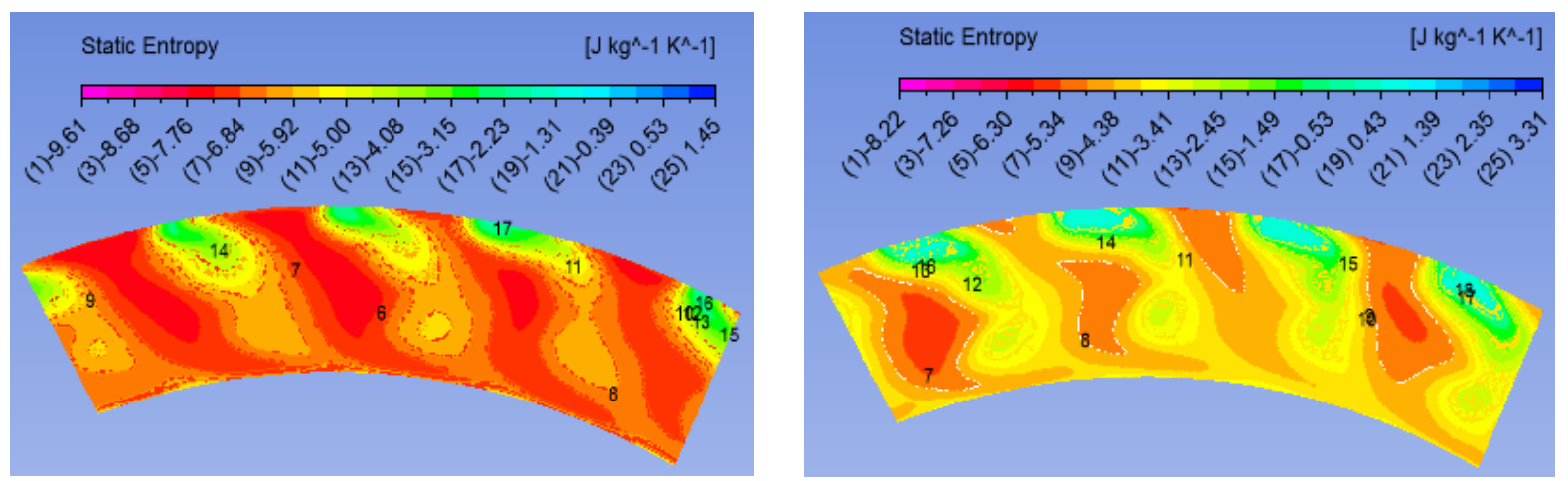

Fig.11. Entropy distribution at rotor outlet for $\mathrm{x} / \mathrm{ch}=0.15$ and $0.5(\phi=0.78)$. 


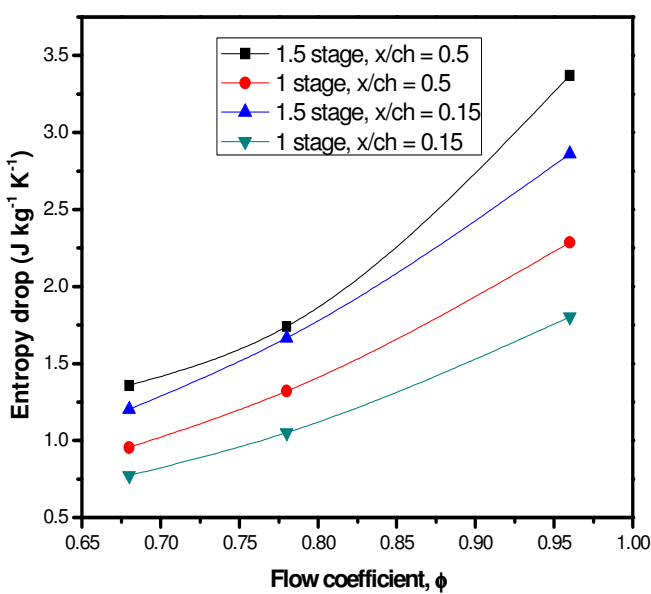

Fig.12. Entropy drop across the stage.

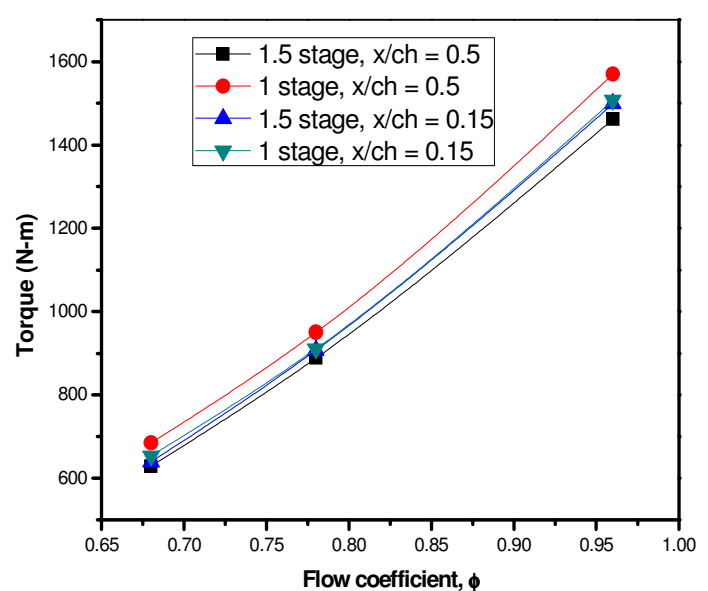

Fig.13. Rotor torque with axial gap.

Table 1. Blade Configuration and flow conditions used in simulation.

\begin{tabular}{|c|c|c|c|c|c|}
\hline $\begin{array}{c}\text { Blade } \\
\text { parameters }\end{array}$ & Nozzle & Rotor & Stator & Flow parameters & Values \\
\hline Number of airfoils & 22 & 28 & 28 & Inlet temperature (K) & 288.97 \\
\hline Hub radius $(\mathrm{mm})$ & 610 & 610 & 610 & Meridional velocity $(\mathrm{m} / \mathrm{s})$ & 22.86 \\
\hline Tip radius $(\mathrm{mm})$ & 762 & 762 & 762 & $\begin{array}{l}\text { Rotational speed of rotor } \\
\text { (RPM) }\end{array}$ & 410 \\
\hline $\begin{array}{l}\text { Tip clearance } \\
(\mathrm{mm})\end{array}$ & 0 & 2.28 & 0 & Inlet flow turbulence & $1 \%$ \\
\hline
\end{tabular}

